\title{
Idiopathic bilateral hypertrophic olivary degeneration
}

\author{
Manchikanti Venkatesh, ${ }^{1}$ Sunitha Vellathussery Chakkalakkoombil, ${ }^{2}$ \\ Pradeep Pankajakshan Nair, ${ }^{3}$ Umar Basha Sowkar ${ }^{4}$
}

${ }^{1}$ Department of Radiodiagnosis, Sri Venkateshwara Medical College Hospital and Research Centre, Pondicherry, India ${ }^{2}$ Department of Radiodiagnosis, Jawaharlal Institute of Postgraduate Medical Education and Research, Pondicherry, India ${ }^{3}$ Department of Neurology, Jawaharlal Institute of

Postgraduate Medical Education and Research, Pondicherry, India ${ }^{4}$ Department of Radiology, Sri Venkateshwara Medical College Hospital and Research Centre, Pondicherry, India

\section{Correspondence to} Dr Sunitha

Vellathussery Chakkalakkoombil drsunithapnair@rediffmail.com

Accepted 28 November 2017

\section{DESCRIPTION}

A 55-year-old man presented with involuntary movements of the tongue and soft palate associated with unsteadiness in walking for a period of 3 months. The patient did not complain of ear clicking. Examination revealed

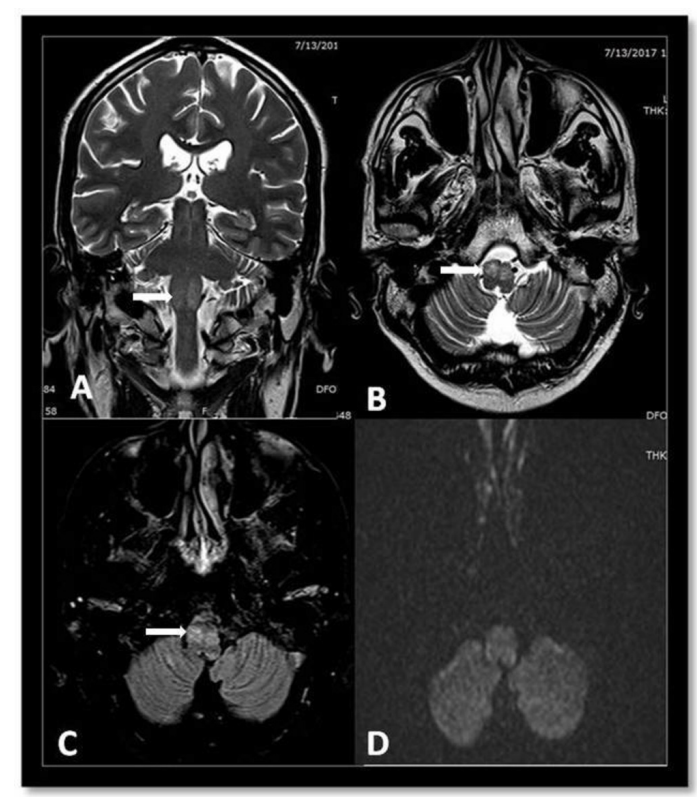

Figure 1 Coronal T2 (A), axial T2 (B), axial Fluid Attenuation Inversion Recovery (FLAIR) (C) and axial diffusion (D) showing enlarged hyperintense inferior olivary nucleus (white arrows) with no diffusion restriction.

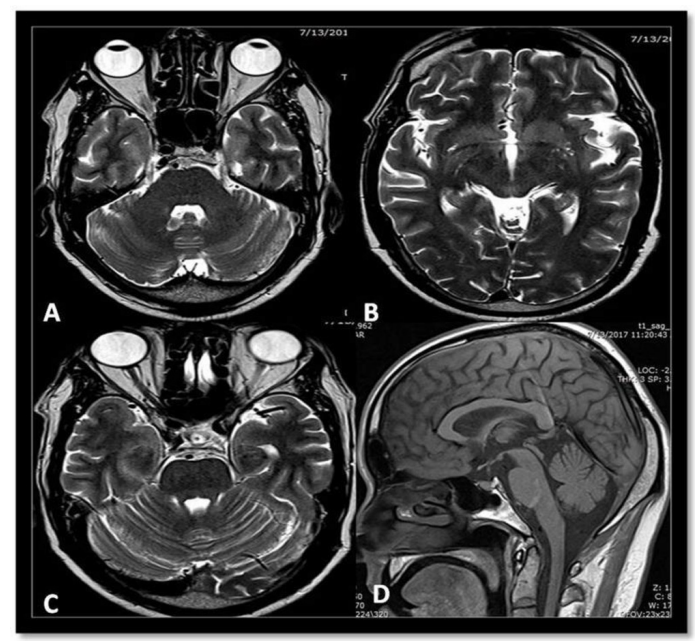

Figure 2 Axial T2 $(A, B, C)$ and sagittal T1 (D) MRI of the brain showing normal midbrain, pons, and cerebral and cerebellar hemispheres.

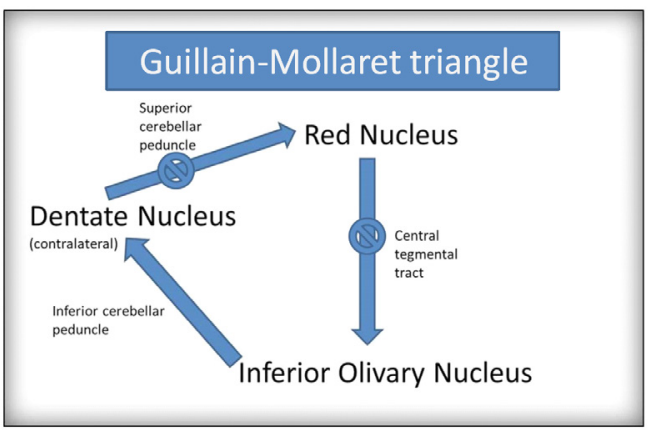

Figure 3 Illustration of Guillain and Mollaret triangle. Disruption (crossed circle) of dentatorubral tract or central tegmental tract can result in trans-synaptic degeneration of the inferior olivary nucleus.

palatal myoclonus, tongue fasciculation and ataxic gait. MRI of the brain showed increased T2 and Fluid Attenuation Inversion recovery (FLAIR) signal intensities in the bilateral inferior olivary complex without diffusion restriction (figure 1). Midbrain, pons, and cerebral and cerebellar parenchyma were normal (figure 2). Imaging features were consistent with bilateral hypertrophic olivary degeneration. Hypertrophic olivary degeneration is a unique type of trans-synaptic neuronal degeneration caused by damage to the dentatorubral pathway or the triangle of Guillain and Mollaret (figure 3). Focal lesions like infarction, haemorrhage, demyelination and trauma involving this neuronal pathway lead to interruption, and following sequential pathological changes are described (table 1$){ }^{1}$

Hypertrophic olivary degeneration is mostly bilateral, and half of bilateral cases may be implicated to primary neurodegenerative process. ${ }^{2}$ Our patient's MRI revealed no abnormality involving

\section{Learning points}

- Hypertrophic olivary degeneration is a rare and unique type of neuronal degeneration mostly due to infarction, infection, demyelination and postsurgery and trauma.

- Bilateral hypertrophic olivary degeneration is more common than unilateral involvement.

- Majority of idiopathic (non-lesional) hypertrophic olivary degeneration is bilateral. 
Table 1 Sequential pathological changes in hypertrophic olivary degeneration

\begin{tabular}{|c|c|}
\hline Time (approximate) & Changes in the olivary nucleus \\
\hline 24 hours & No olivary change \\
\hline $2-7$ days & Degeneration of white matter olivary capsule \\
\hline 3 weeks & Mild olivary hypertrophy without glial reaction \\
\hline 8.5 months & $\begin{array}{l}\text { Olivary enlargement occurs with hypertrophy of both } \\
\text { neurons and axons }\end{array}$ \\
\hline 9.5 months & $\begin{array}{l}\text { Olivary pseudohypertrophy (in which there is neuronal } \\
\text { dissolution with gemistocytic astrocytes) }\end{array}$ \\
\hline $3-4$ years & Olivary atrophy is evident \\
\hline
\end{tabular}

the Guillain and Mollaret triangle. Hence the exact cause for hypertrophic olivary degeneration is not known. According to a study conducted by $\mathrm{Gu}$ et al, one in every five patients of hypertrophic olivary degeneration was idiopathic, and most of the idiopathic cases were showing bilateral hypertrophic olivary degeneration.
Contributors MV: conception and design, acquisition of data or analysis and interpretation of data. SVC: drafting the article or revising it critically for important intellectual content. PPN: final approval of the version published. UBS: agreement to be accountable for the article and to ensure that all questions regarding the accuracy or integrity of the article are investigated and resolved.

Competing interests None declared.

Patient consent Obtained.

Provenance and peer review Not commissioned; externally peer reviewed.

(C) BMJ Publishing Group Ltd (unless otherwise stated in the text of the article) 2017. All rights reserved. No commercial use is permitted unless otherwise expressly granted.

\section{REFERENCES}

1 Van Eetvelde R, Lemmerling M, Backaert T, et al. Imaging features of hypertrophic olivary degeneration. J Belg Soc Radiol 2016;100:71.

2 Konno T, Broderick DF, Tacik P, et al. Hypertrophic olivary degeneration: a clinicoradiologic study. Parkinsonism Relat Disord 2016;28:36-40.

3 Gu CN, Carr CM, Kaufmann TJ, et al. MRI findings in nonlesional hypertrophic olivary degeneration. J Neuroimaging 2015;25:813-7.

Copyright 2017 BMJ Publishing Group. All rights reserved. For permission to reuse any of this content visit

http://group.bmj.com/group/rights-licensing/permissions.

BMJ Case Report Fellows may re-use this article for personal use and teaching without any further permission.

Become a Fellow of BMJ Case Reports today and you can:

- Submit as many cases as you like

- Enjoy fast sympathetic peer review and rapid publication of accepted articles

Access all the published articles

Re-use any of the published material for personal use and teaching without further permission

For information on Institutional Fellowships contact consortiasales@bmjgroup.com

Visit casereports.bmj.com for more articles like this and to become a Fellow 